\title{
Toward a Coherent Look at Federal Activity in MS\&E
}

\section{An Interview with}

Allan Bromley

Dr. D. Allan Bromley, President

Bush's science adviser, is firmly committed to the administration's gaining a better understanding of materials science and engineering and then going forth with a cohesive program from there. The MRS BULLETIN interviewed him on July 17 in his office in the Old Executive Office Building. Following is an excerpt of that interview.

BULLETIN: The Department of Commerce recentiy issued a report that identified advanced materials as by far the leading emerging technology. Is special consideration being provided to spur this critical technology sector?

BROMLEY: First of all, we are preparing so that next year we will work with the Office of Management and Budget to develop a coherent federal program that spans all the agencies together to get a coherent look for the first time at federal activity in materials science and engineering. I have long thought that was an orphan area, not only in government but in many of the universities, because it doesn't fit into department or agency boundaries.

At the same time, the President's Council of Advisers on Science and Technology, chaired by Ralph Gomory, the former chief scientist at IBM and now president of the Sloan Foundation, will be focusing on advanced materials and manufacturing as two very important areas that bear on economic competitiveness.

Third, the new National Critical Materials Council will be focusing specifically on advanced materials and will be comparing the program planned for research in that area next fall.

BULLETIN: What role is COMAT taking to corral such data?
BROMLEY: COMAT is the FCCSET (Federal Coordinating Committee for Science and Engineering Technology) committee that deals with science, and it will be the one that carries out this coordination and integration. It will also be the one that carries out this crosscut.

BULLETIN: Will the Materials Science and Engineering Study of the National Academy of Sciences, and its followup regional meetings, impact the size and shape of the field?

BROMLEY: Very much. We have encouraged Dr. Frank Press [president of the National Academy of Sciences] to hold the regional meetings, and one or another of my associate directors has attended each of the meetings. We expect to learn a lot from those meetings, and we believe the report itself represents a major contribution in bringing this whole field into focus.

BULLETIN: Is there a clear distinction between critical materials and advanced materials within the Bush administration?

BROMLEY: I think there is. Critical materials are those that are of strategic importance to the nation. Advanced materials have properties that have not been seen before.

BULLETIN: Is the National Critical Materials Council not involved with advanced materials?

BROMLEY: Yes, it is. The fact that it is called the National Critical Materials Council doesn't mean that it focuses only on critical materials, although it does publish an interval report on critical materials. It also focuses in a major way on advanced materials and is responsible for developing the national program plan for advanced materials. It also will take the report of the [National] Commission on Superconductivity and update that on a periodic basis.

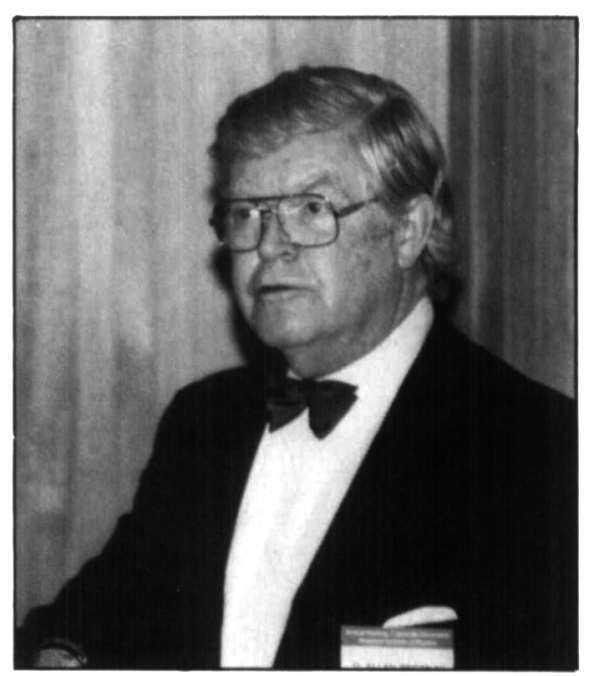

D. Allan Bromley, Assistant to the President for Science and Technology, and Director of the Office of Science and Technology Policy.

BULLETIN: Are you satisfied with the level of visibility and effort from NCMC at this time?

BROMLEY: Inasmuch as we only held the first meeting of the NCMC July 9,1 believe that we are off to a fine start. I recognize that the whole Council had a bit of a rocky beginning. Things are now on track.

BULLETIN: Do you envision a constructive new role for the technical and professional societies to better coordinate the scientific, technological, and industrial needs of the country?

BROMLEY: Yes. We in this office have already been in touch with most of the societies, and my associate directors Gene Wong and Bill Phillips, in particular, have been talking with a number of them. We look upon them as real resources that can bring to us in synthesized fashion the opinions of some of the leading figures in the field.

MRS Office of Public Affairs Washington, DC 


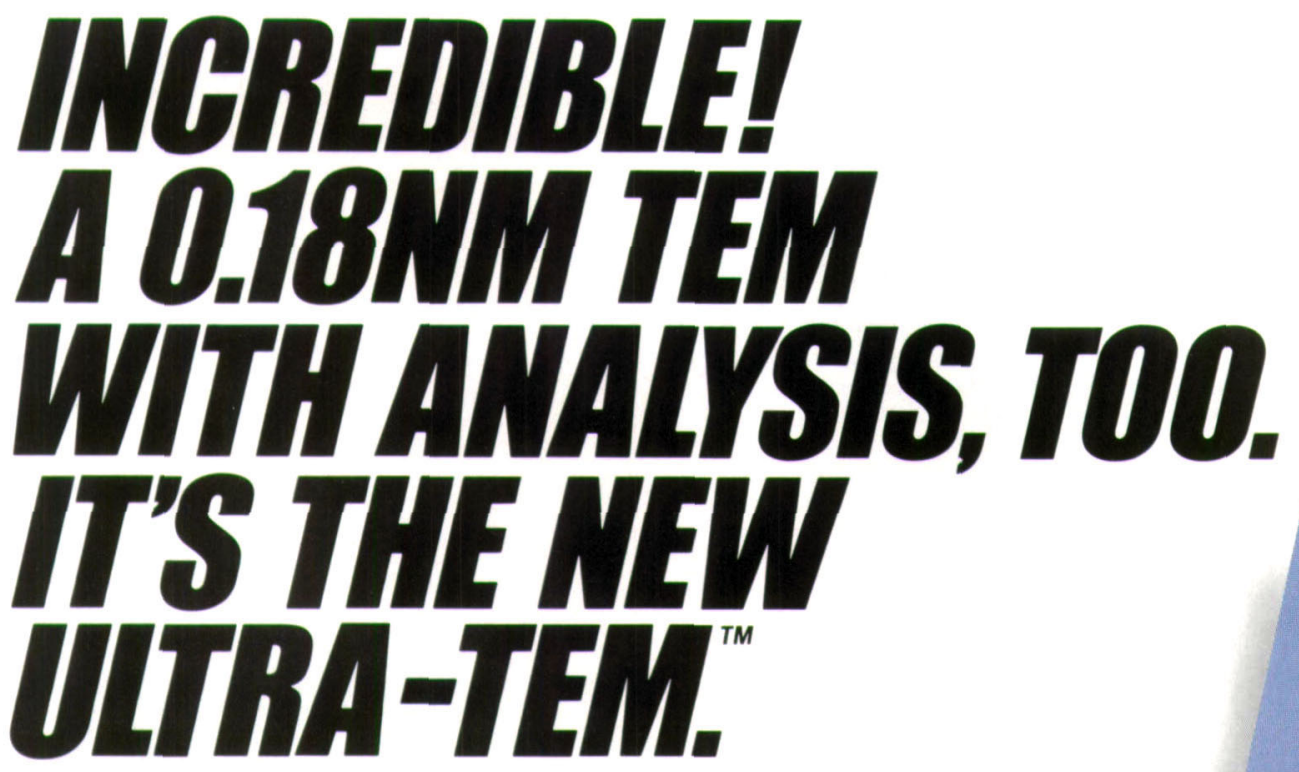

Please visit Booth No. 603 at the MRS Show in Boston, November 28-30, 1989.

Ultra-TEM. ISI's new Model EM-002B. There's nothing else like it. Anywhere...

Just imagine the TEM work you could do with $0.18 \mathrm{~nm}$ resolution. (And that's at $200 \mathrm{kV}$, by the way, not $400 \mathrm{kV}$.)

Now, imagine that same instrument also giving you nano-probe compositional analysis: EDS. MBED. EELS. CBD.

Not only that, but letting you go from

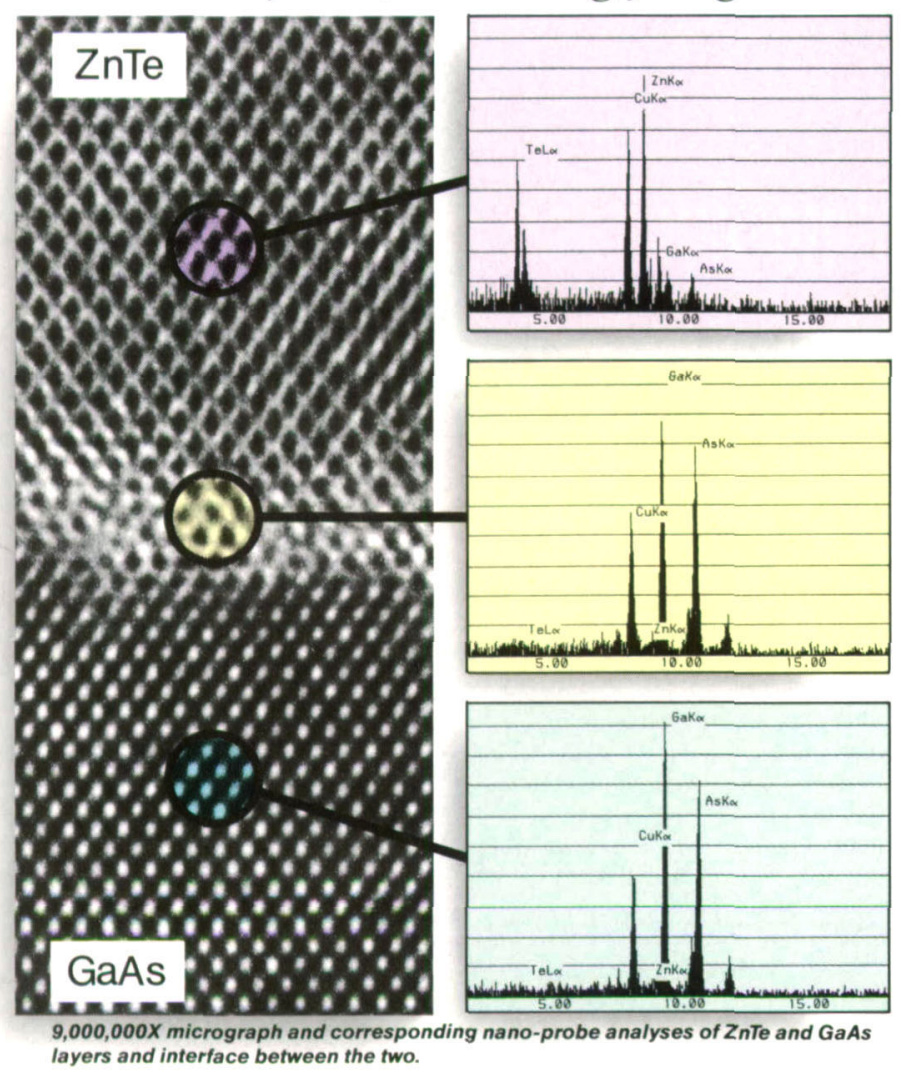

regular imaging to nano-probe. Instantly. At the touch of a button.

So probe placement is always absolutely precise. With no need for scanning attachments.

And as if that were not enough, imagine the Ultra-TEM costing about half what you'd expect to pay for a $0.18 \mathrm{~nm}$ TEM with $n o$ analysis...

We consider this new research TEM a pretty significant breakthrough. But we're more interested in your evaluation...

Get all the details on the new UltraTEM Model EM-002B. Call or write, today:

International Scientific Instruments, 6940 Koll Center Pkwy, Pleasanton, CA 94566. (800) 538-6850 or (415) 462-2212. Fax: 415-462-2234.

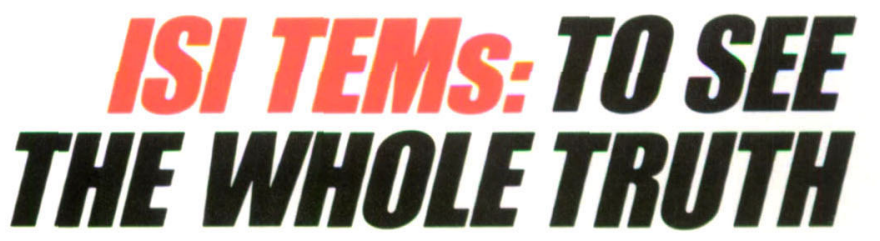

